\title{
Solidification of Al-Sn-Cu Based Immiscible Alloys under Intense Shearing
}

\author{
H.R. KOTADIA, E. DOERNBERG, J.B. PATEL, Z. FAN, and R. SCHMID-FETZER
}

The growing importance of Al-Sn based alloys as materials for engineering applications necessitates the development of uniform microstructures with improved performance. Guided by the recently thermodynamically assessed $\mathrm{Al}-\mathrm{Sn}-\mathrm{Cu}$ system, two model immiscible alloys, $\mathrm{Al}-45 \mathrm{Sn}-10 \mathrm{Cu}$ and $\mathrm{Al}-20 \mathrm{Sn}-10 \mathrm{Cu}$, were selected to investigate the effects of intensive melt shearing provided by the novel melt conditioning by advanced shear technology (MCAST) unit on the uniform dispersion of the soft Sn phase in a hard Al matrix. Our experimental results have confirmed that intensive melt shearing is an effective way to achieve fine and uniform dispersion of the soft phase without macro-demixing, and that such dispersed microstructure can be further refined in alloys with precipitation of the primary Al phase prior to the demixing reaction. In addition, it was found that melt shearing at $200 \mathrm{rpm}$ and 60 seconds will be adequate to produce fine and uniform dispersion of the Sn phase, and that higher shearing speed and prolonged shearing time can only achieve minor further refinement.

DOI: $10.1007 / \mathrm{s} 11661-009-9918-\mathrm{x}$

(C) The Minerals, Metals \& Materials Society and ASM International 2009

\section{INTRODUCTION}

TERNARY Al-Sn-Cu based alloys have been used for many years for the production of self-lubricant bearing materials. They have been commonly accepted as having excellent tribological, mechanical, and physical properties. ${ }^{[1-3]}$ The $\mathrm{Sn}$ is a necessary component in bearing applications because of its excellent antiwelding characteristics with iron, its low modulus, and its low strength, which provides suitable surface properties. On the other hand, $\mathrm{Cu}$ has been traditionally added in bearing alloys to provide solid solution strengthening of the Al matrix, improving its resistance to fatigue failure. ${ }^{[4]}$ The combination of the two alloy additions provides a soft and ductile dispersed phase in a hard and strong matrix, producing alloys appropriate for bearing applications. ${ }^{[1-10]}$

One of the major challenges in the processing of $\mathrm{Al}-\mathrm{Sn}-\mathrm{Cu}$ alloys is that there is a large stable liquid miscibility gap in the system, through which many technical alloys must pass during solidification. This liquid immiscibility causes severe segregation mainly due to the large density difference between the Al-rich and Sn-rich liquids, compounded by large temperature gradient during solidification. To control this phase separation, considerable attempts have been made by several authors. ${ }^{[1,2,9]}$ However, the nature of the phase separation and solidification of immiscible alloys has

H.R. KOTADIA, Doctoral Student, J.B. PATEL, Research Fellow, and Z. FAN, Professor, are with the BCAST (Brunel Centre for Advanced Solidification Technology), Brunel University, Uxbridge, UB8 3PH, United Kingdom. Contact e-mail: h.kotadia@brunel.ac.uk E. DOERNBERG, Doctoral Student, and R. SCHMID-FETZER, Professor, are with the Clausthal University of Technology, Institute of Metallurgy, D-38678 Clausthal-Zellerfeld, Germany.

Manuscript submitted February 16, 2009. remained an unsolved problem. ${ }^{[11]}$ Therefore, understanding the precise solidification paths of immiscible alloys is scientifically and technically significant.

Recently, with the development of materials science in zero-gravity environment, increased attention has been paid to the solidification of immiscible alloys under microgravity and highly undercooled conditions. ${ }^{[12]}$ Although it has been shown that the monotectic reaction is very sensitive to the level of gravity and the level of undercooling prior to crystallization, ${ }^{[12]}$ results are still unsatisfactory, as even under microgravity conditions, a coarse phase separation occurs due to Marangoni motion. ${ }^{[1,2,9,13]}$ The development of new processing techniques, therefore, becomes an inevitable task for both the materials community and the automobile industry. Fan and co-workers ${ }^{[14]}$ have developed a melt conditioning by advanced shear technology (MCAST) unit to study the solidification behavior of aluminum and magnesium alloys under intensive shearing, which can also be used to study the solidification behavior of immiscible systems.

In order to better understand the solidification of $\mathrm{Al}-\mathrm{Sn}-\mathrm{Cu}$ alloys as well as their behavior during the shearing process, two approaches have been combined. Computational thermodynamics has been used to identify alloys that are promising for the production of bearing materials using the MCAST unit. This study includes thermodynamic calculations based on the results of previous work described elsewhere. ${ }^{[15,16]}$ By using the MCAST unit, the two most promising alloys, $\mathrm{Al}-45 \mathrm{Sn}-10 \mathrm{Cu}$ and $\mathrm{Al}-20 \mathrm{Sn}-10 \mathrm{Cu}$ (all compositions in this article are given in weight percent unless otherwise stated), were successfully synthesized with well-dispersed microstructures throughout the entire volume of the samples. The influence of the viscosity of the system as well as the shear force on the nature of primary $\mathrm{Al}$ and Sn phase particles was investigated for these alloys. 
In this article, we refer to "droplets" and "particles" as liquid phases and solidified liquid phases, respectively. The phase transformations of both alloys during solidification were also followed using differential scanning calorimetry (DSC), complementing the calculated results.

\section{THERMODYNAMICS OF THE Al-Sn-Cu SYSTEM}

\section{A. Phase Equilibrium in the Al-Sn-Cu Alloys}

Recently, Mirkovic et al. ${ }^{[15]}$ have critically assessed the ternary Al-Sn-Cu system. They studied the complex features of the Al-Sn-Cu phase diagram, dominated by ternary liquid demixing, using a combination of the CALPHAD thermodynamic modeling ${ }^{[17]}$ approach and DSC experimental studies as well as microstructural analysis. Their results showed that addition of the third component, copper, to Al-Sn alloys causes a pronounced liquid demixing, forming an isolated miscibility gap in the ternary system. It was also shown how seemingly small changes in alloy composition can result in drastically different microstructures.

Figure 1(a) shows the calculated liquidus surface for the $\mathrm{Cu}$-poor section of the $\mathrm{Al}-\mathrm{Sn}-\mathrm{Cu}$ alloy system. A large ternary stable liquid miscibility gap marked $\mathrm{L}^{\prime}+\mathrm{L}^{\prime \prime}$ has developed from the metastable liquid miscibility gaps in both the $\mathrm{Al}-\mathrm{Sn}$ and $\mathrm{Cu}-\mathrm{Sn}$ binary

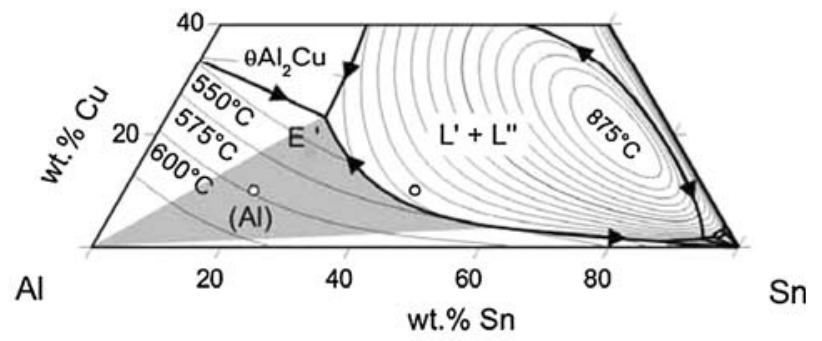

(a)

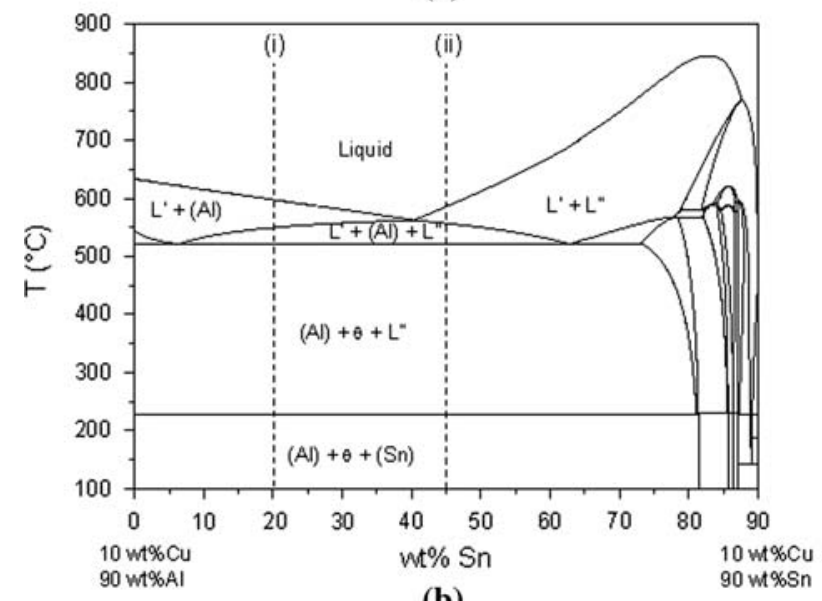

(b)

Fig. 1-(a) $\mathrm{Cu}$-poor section of the calculated $\mathrm{Al}-\mathrm{Sn}-\mathrm{Cu}$ liquidus surface. ${ }^{[12]}(b)$ Calculated vertical section at constant $10 \mathrm{wt}$ pct $\mathrm{Cu}$. Liquid-phase notation is distinguished where appropriate, $\mathrm{L}^{\prime}=\mathrm{Al}-$ rich and $\mathrm{L}^{\prime \prime}=\mathrm{Sn}$-rich liquid and (i) and (ii) stand for Al-20Sn-10Cu and $\mathrm{Al}-45 \mathrm{Sn}-10 \mathrm{Cu}$ alloys, respectively. systems. Alloys with an overall composition within the miscibility gap will separate into two distinct liquids upon cooling below a critical temperature. The $\mathrm{L}^{\prime \prime}$ liquid is rich in $\mathrm{Sn}$ and therefore has a much higher density than the $\mathrm{L}^{\prime}$ liquid, which is rich in Al. Upon further cooling, these two-phase alloys will begin solidifying by precipitating aluminum-rich solid solution, Al, from both liquids. The solidification stages that then follow are discussed in Section IV-A. Another set of alloys with a total composition lying within the region marked by gray shading on the liquidus surface will first undergo precipitation of $\mathrm{Al}$ before the residual liquid reaches a composition on the surface of the miscibility gap, causing subsequent demixing. After demixing, the solidifications of $\mathrm{L}^{\prime}$ and $\mathrm{L}^{\prime \prime}$ in these samples are similar to those of samples that experience primary demixing.

\section{B. Alloy Selection Using Computational Thermodynamics}

Alloys should be identified that show promising properties for the production of $\mathrm{Al}-\mathrm{Sn}-\mathrm{Cu}$ bearing alloys using the MCAST process. These are alloys that undergo some demixing in the liquid phase so that soft $\mathrm{Sn}$-rich particles can be found in a hard Al matrix in the final solidified microstructure. The exact amount of each phase present in the final microstructure strongly affects the mechanical properties of the alloy. For optimal processing using the MCAST unit, an alloy should be chosen with a relatively low-temperature sensitivity of the solid fraction during cooling, i.e., a change in temperature over an easily controllable interval should invoke only a relatively small change in the solid fraction of the alloy. In this way, the effective viscosity of the melt can be easily controlled and chosen for optimal processing. In order to explore the possible advantages of increasing the effective viscosity of the melt before demixing in the liquid phase begins, one alloy out of the gray area in Figure 1(a) should be chosen, which shows Al solid solution precipitation and then liquid demixing, and one alloy with primary demixing, i.e., an overall composition within the miscibility gap in Figure 1(a). In addition, the alloy compositions should be selected for ease of processing using the MCAST unit. Based on the preceding consideration, the following two alloys have been selected for this work: Al-20Sn-10Cu and Al-45Sn-10Cu (wt pct). Both alloys have been marked (i) and (ii), respectively, in Figure 1(b).

Using Pandat, ${ }^{[18]}$ a software package for thermodynamic calculations, the solidification paths of a large range of alloys were investigated in order to find just a few alloys that fit all of the preceding criteria. The development of the phases present at each stage of solidification in the two chosen alloys can be seen in the ternary phase diagram section at $10 \mathrm{wt}$ pet $\mathrm{Cu}$ shown in Figure 1(b). In this diagram, however, no information can be gained about the amount of each phase present, since the lever rule cannot be applied in such sections. The results of further thermodynamic calculations are shown in Figure 2, where the phase evolution in the microstructure during cooling of the two chosen alloys is 


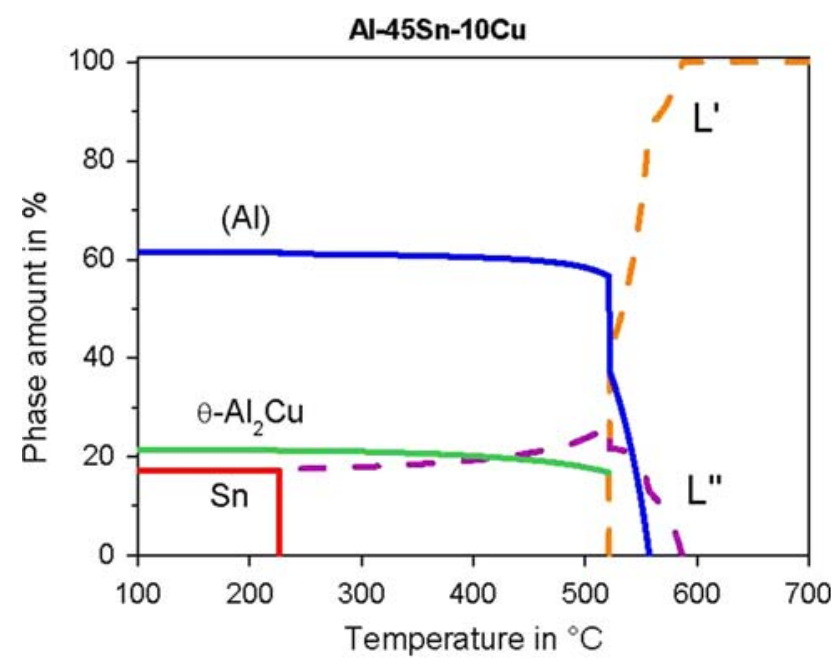

(a)

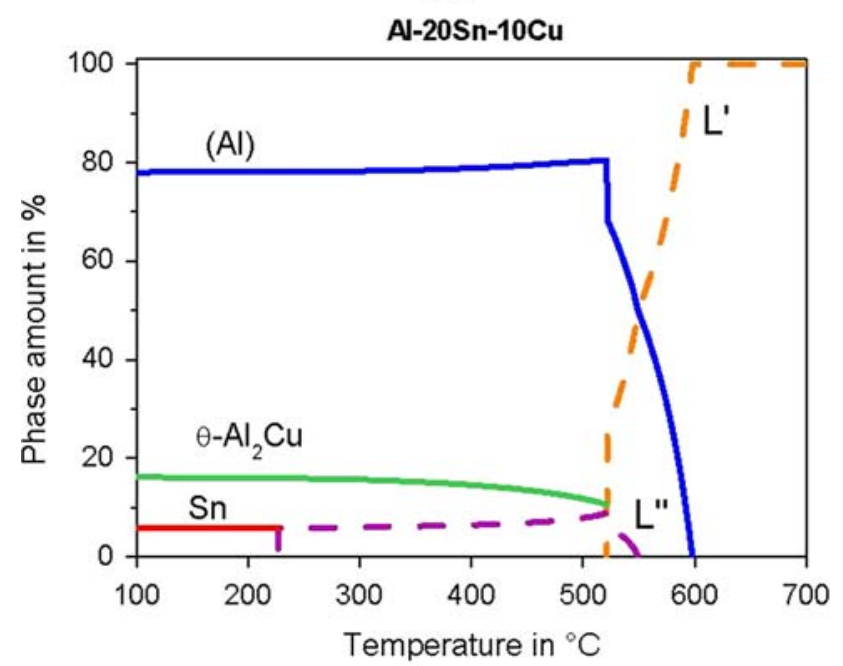

(b)

Fig. 2-Thermodynamic calculation of the phase development in (a) $\mathrm{Al}-45 \mathrm{Sn}-10 \mathrm{Cu}$ alloy and (b) $\mathrm{Al}-20 \mathrm{Sn}-10 \mathrm{Cu}$ alloy.

shown in the form of the calculated phase fraction as a function of temperature. These diagrams are best read from right to left, and the final phase distribution in the microstructure can be read from the left-hand axes.

The Al-45Sn-10Cu alloy (ii) lies within the liquid miscibility gap (Figures 1(a) and (b)), and therefore shows primary demixing before the primary Al phase precipitates from the $\mathrm{L}^{\prime}$. This alloy shows a final amount of Sn of 17 at. pct, and the temperature sensitivity of the solid fraction during cooling is $\sim 1 \mathrm{pct} / \mathrm{K}$. The Al-20Sn$10 \mathrm{Cu}$ alloy (i) shows primary precipitation of $\mathrm{Al}$ before demixing and a final Sn fraction of 6 at. pct, and the temperature sensitivity of solid fraction is also $\sim 1 \mathrm{pct} / \mathrm{K}$.

\section{EXPERIMENTAL PROCEDURES}

\section{A. Material Preparation}

The two selected alloys, Al-45Sn-10Cu and Al-20Sn$10 \mathrm{Cu}$, were prepared from commercially pure aluminum and 99.99 wt pet pure $\mathrm{Sn}$ and $\mathrm{Cu}$ in a clay graphite crucible using an electrical resistance furnace. The melt was homogenized for at least 2 hours at $200{ }^{\circ} \mathrm{C}$ above the critical temperature, $T_{c}$ (where both L'and $\mathrm{L}^{\prime \prime}$ liquids are completely miscible).

\section{B. DSC Studies}

The phase transition temperatures of both alloys were investigated using a differential scanning calorimeter (NETZSCH STA 409PC instrument). The temperature range was from $200{ }^{\circ} \mathrm{C}$ to $700{ }^{\circ} \mathrm{C}$. The various scanning rates from 1 to $20 \mathrm{~K} / \mathrm{min}$ were employed, and both heating and cooling processes were tested. Each specimen mass was between 15 and $20 \mathrm{mg}$ and was placed in an alumina crucible $(12.5-\mathrm{mm}$ outer diameter and 7.5-mm height) with Ar flow for testing in order to avoid oxidation. Average transition temperatures are taken from 3 different DSC scans of each alloy.

\section{MCAST Unit}

The MCAST unit is designed to create a microstructure in which a softer phase is distributed finely and uniformly in a harder matrix. The MCAST unit consists of specially-designed profiles of the closely intermeshing screws, which are self-wiping and co-rotating. The flow inside the MCAST unit is characterized by a high shear rate and a high intensity of turbulence, which ensures powerful dispersive mixing at a very fine level. The high intensive shear also provides a uniform temperature, uniform chemical composition, and well-dispersed nucleation site in the melt. The intermediate shear rate, $\dot{\gamma}$, is found in the gap between the tip of a screw flight and barrel surface and is given by the following equation:

$$
\dot{\gamma}=N \pi\left(\frac{D}{G}-2\right)
$$

where $N$ is the rotation speed of the screw, $D$ is the outer diameter of the screw, and $G$ is the gap between the screw flight and barrel surface. A detailed explanation of fluid flow in the MCAST unit is described elsewhere. $^{[8,14,19-24]}$

Before beginning the experiments, the MCAST unit was heated to the semisolid region (processing temperature, $T_{p}$ ) of the alloy to be used. The melt was poured into the MCAST unit well above $T_{c}$ to avoid liquidphase separation before shearing commences. After shearing, the conditioned melt was cast with a highpressure die-casting (HPDC) process for microstructural investigations. The combination of MCAST and HPDC is called the MC-HPDC process. It should be noted that the HPDC process gives high cooling rates (up to $\sim 1000 \mathrm{Ks}^{-1}$ ), which in turn reduce any gravitational segregation.

For solidification and microstructural comparison purposes, melt was directly transferred to the conical shape steel mold and HPDC machine without shearing, which are referred to as gravity casting and the conventional HPDC process, respectively. 


\section{Microscopy and Quantitative Metallography}

Samples for microstructural examination were cut from the HPDC and MC-HPDC castings and mounted in Bakelite. The mounted specimens were ground using standard techniques with $\mathrm{SiC}$ abrasive paper and polished with a $0.25-\mu \mathrm{m}$ diamond suspension solution supplied by Struers Ltd., West Midlands, UK. The microstructures were observed without etching under a Zeiss optical microscope $(\mathrm{OM})$ equipped with an Axioshop 2 MAT0 camera, which was used for observation and quantitative analysis, while a JEOL JXA-840A scanning electron microscope (SEM) equipped with an energy dispersive spectroscopy facility at an accelerating voltage of $20 \mathrm{kV}$ was used to achieve higher magnification in areas of interest, as well as to quantitatively identify each phase region.

Quantitative metallographic analysis was carried out to analyze the dispersion of the soft phase in the hard matrix and the effect of the shearing time, shearing temperature, and shearing speed on this distribution for the optimization of the MC-HPDC process. In the process of microstructural characterization, the equivalent diameter $(d)$ and shape factor $(F)$ were calculated from

$$
\begin{aligned}
& d=\sqrt{4 A / \pi} \\
& F=4 \pi A / P^{2}
\end{aligned}
$$

where $A$ is the total area and $P$ is the peripheral length of the primary particles. When $F$ is equal to 1 , it represents a perfectly spherical particle. To characterize the distribution of the $\mathrm{Sn}$ particles in the $\mathrm{Al}$ matrix, the statistical Quadrat method was used. ${ }^{[25]}$ The Quadrat method was performed on 15 images of different areas within each sample.

\section{RESULTS AND DISCUSSION}

\section{A. Microstructural Evolution during Gravity Die Casting}

As mentioned in Section II-B, the solidification paths of the two chosen alloys are expected to differ significantly in the first stages. While the Al-45Sn-10Cu shows demixing of the liquid phase before commencement of solidification, the Al-20Sn-10Cu first shows precipitation of $\mathrm{Al}$ before demixing occurs. This can be seen in the microstructures of each alloy after conventional casting in the metallic mold shown in Figures 3(a) and (b). The most significant difference between these two micrographs is the agglomeration of $\mathrm{Sn}$ (white phase in SEM images) in the Al-45Sn-10Cu sample (Figure 3(a)), while $\mathrm{Sn}$ in the Al-20Sn-10Cu sample (Figure 3(b)) is regularly distributed between the other phases in the microstructure, which indicates that the liquid separation occurred after primary solidification in the Al-20Sn-10Cu sample.

In the following, the microstructural formation in each sample alloy will be discussed with respect to the calculated solidification path, which is also shown in the phase fraction diagrams in Figure 2 as well as the measured DSC signal traces shown in Figure 4.
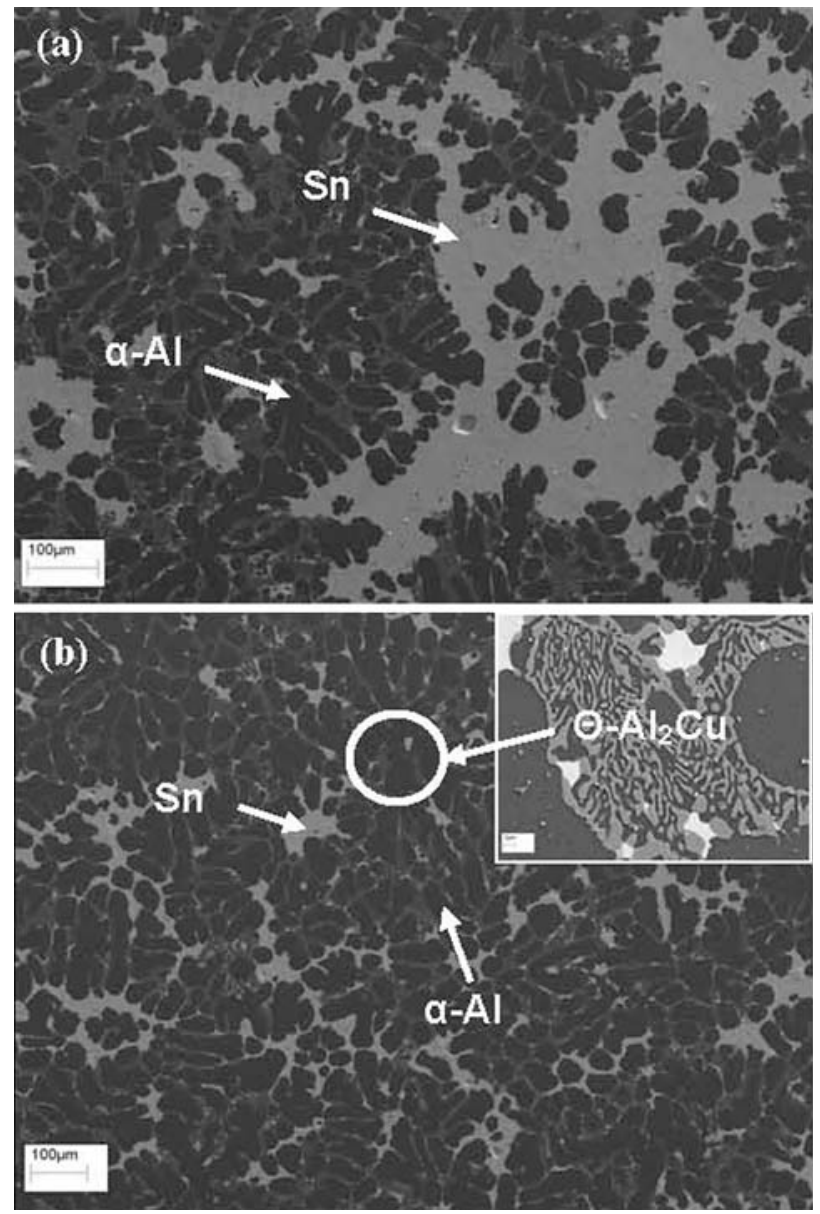

Fig. 3-SEM micrographs from (a) $\mathrm{Al}-45 \mathrm{Sn}-10 \mathrm{Cu}$ alloy and (b) Al-20Sn-10Cu alloy of the samples cast into a steel mold directly from $650{ }^{\circ} \mathrm{C}$. Inset in (b) shows a eutectic region at higher magnification. Note that significant Sn-rich phase segregation occurred in the $\mathrm{Al}-45 \mathrm{Sn}-10 \mathrm{Cu}$ alloy, whereas in the $\mathrm{Al}-20 \mathrm{Sn}-10 \mathrm{Cu}$ alloy, the $\mathrm{Sn}$-rich phase is trapped between the primary $\mathrm{Al}$ dendritic phases.

When the Al-45Sn-10Cu sample is cooled below the surface of the liquid miscibility gap $\left(587{ }^{\circ} \mathrm{C}\right)$, droplets of $\mathrm{L}^{\prime \prime}$ liquid begin to separate from the remaining $\mathrm{L}^{\prime}$. These droplets are nucleated mainly in the areas near the wall of the casting, where the undercooling is greatest. As the composition of these liquids is originally quite similar, the interfacial energy, and therefore the measurable enthalpy effect of this reaction, is very low. As a result, no signal can be detected in the DSC experiment. Over the next $30^{\circ} \mathrm{C}$, the amount of $\mathrm{L}^{\prime \prime}$ grows and the droplets move uninhibited through the melt, coagulating as they settle and grow. The motion of $\mathrm{L}^{\prime \prime}$ droplets through the unstirred melt can be attributed to two factors. The first factor affecting the direction of droplet motion is the denser nature of the Sn-rich L" (dark gray in the OM images) than $\mathrm{L}^{\prime}$ (white in the OM images) in Figure 5. Therefore, $L^{\prime \prime}$ droplets sink toward the bottom of the casting due to gravity (Figure 5(a)), which is described by the well-known Stokes motion, for the settling velocity. ${ }^{[1,2,5,11]}$ The second factor affecting the direction of droplet motion is the temperature gradient. The droplets migrate from a low-temperature region to high-temperature regions, described by the well-known 
Marangoni motion. ${ }^{[1,2,26-28]}$ The $\mathrm{OM}$ images in Figure 5(b) reveal that the motion of the Sn droplets, as indicated by their elongated shape, is perpendicular to the main axis of the mold.

Upon further cooling of the Al-45Sn-10Cu sample, an Al solid solution and more $\mathrm{L}^{\prime \prime}$ is precipitated from the $\mathrm{L}^{\prime}$ phase. The first (most-right-hand) signal on the DSC curve marks the beginning of this precipitation reaction at $559.5^{\circ} \mathrm{C}$. This is closely followed by the monotectic reaction, $\mathrm{M}: \mathrm{L}^{\prime}=\mathrm{L}^{\prime \prime}+(\mathrm{Al})+\theta-\mathrm{Al}_{2} \mathrm{Cu}$, occurring in the regions that are dominated by $\mathrm{L}^{\prime}$. This reaction occurs at $524{ }^{\circ} \mathrm{C}$ according to the calculation and at

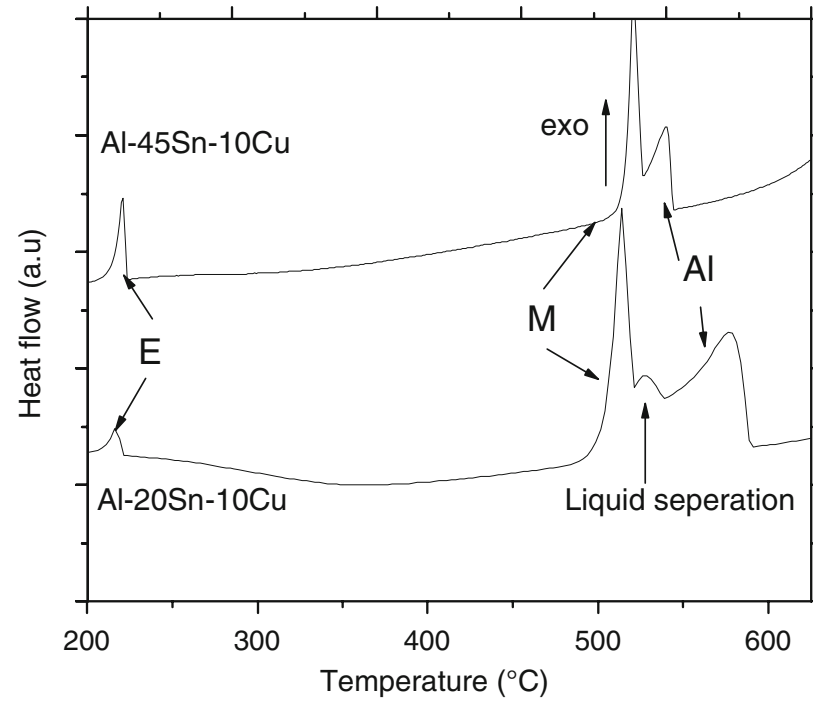

Fig. 4 -DSC traces of $\mathrm{Al}-45 \mathrm{Sn}-10 \mathrm{Cu}$ and $\mathrm{Al}-20 \mathrm{Sn}-10 \mathrm{Cu}$ alloys at a cooling rate of $10 \mathrm{~K} / \mathrm{min}$. $526.8^{\circ} \mathrm{C}$ in the DSC measurement. The fine microstructure corresponding to this stage of solidification can be seen between the dark primary $\mathrm{Al}$ dendritic phases in the magnified insert in Figure 3(b). Finally, the remaining $\mathrm{L}^{\prime \prime}$ solidifies to form predominantly pure Sn particles (white in the SEM images) via the eutectic reaction, E: $\mathrm{L}^{\prime \prime}=(\mathrm{Sn})+(\mathrm{Al})+\theta-\mathrm{Al}_{2} \mathrm{Cu}$. This reaction was detected at $228.3{ }^{\circ} \mathrm{C}$, while the thermodynamic calculations suggest it should occur at $227^{\circ} \mathrm{C}$. In the Al-45Sn$10 \mathrm{Cu}$ alloy, the CALPHAD prediction is in good agreement with experimental data.

According to the CALPHAD calculation, the Al-20Sn-10Cu sample should begin to solidify at around $598{ }^{\circ} \mathrm{C}$. The DSC experiment shows a small amount of undercooling, where the first (most-right-hand) peak at $592{ }^{\circ} \mathrm{C}$ represents the beginning of $\mathrm{Al}$ precipitation. These primary grains/dendrites grow to a phase fraction of around 50 at. pet before the first demixing of the remaining melt occurs at $550{ }^{\circ} \mathrm{C}$. In this case, the composition of $\mathrm{L}^{\prime \prime}$ differs substantially from the parent liquid phase, and a small enthalpy effect can be detected in the DSC experiment. The $\mathrm{L}^{\prime \prime}$ droplets form throughout the sample, and while similar factors as described previously (gravity and temperature gradient) also apply here, the motion of these droplets is inhibited by the solid particles and increased viscosity of the alloy. As a result, coagulation of the $\mathrm{L}^{\prime \prime}$ droplets does occur, as shown in Figures 6(a) and (b), but not to the same extent as in the Al-45Sn-10Cu sample. Upon further cooling below $550{ }^{\circ} \mathrm{C}$, the remaining liquid in the Al-20Sn-10Cu sample follows similar stages of solidification, as described previously, for the Al-45Sn-10Cu sample. First, $\mathrm{Al}$ and a small amount of $\mathrm{L}^{\prime \prime}$ is precipitated in the $\mathrm{L}^{\prime}$ regions, before this region solidifies almost completely in the monotectic reaction. Finally,

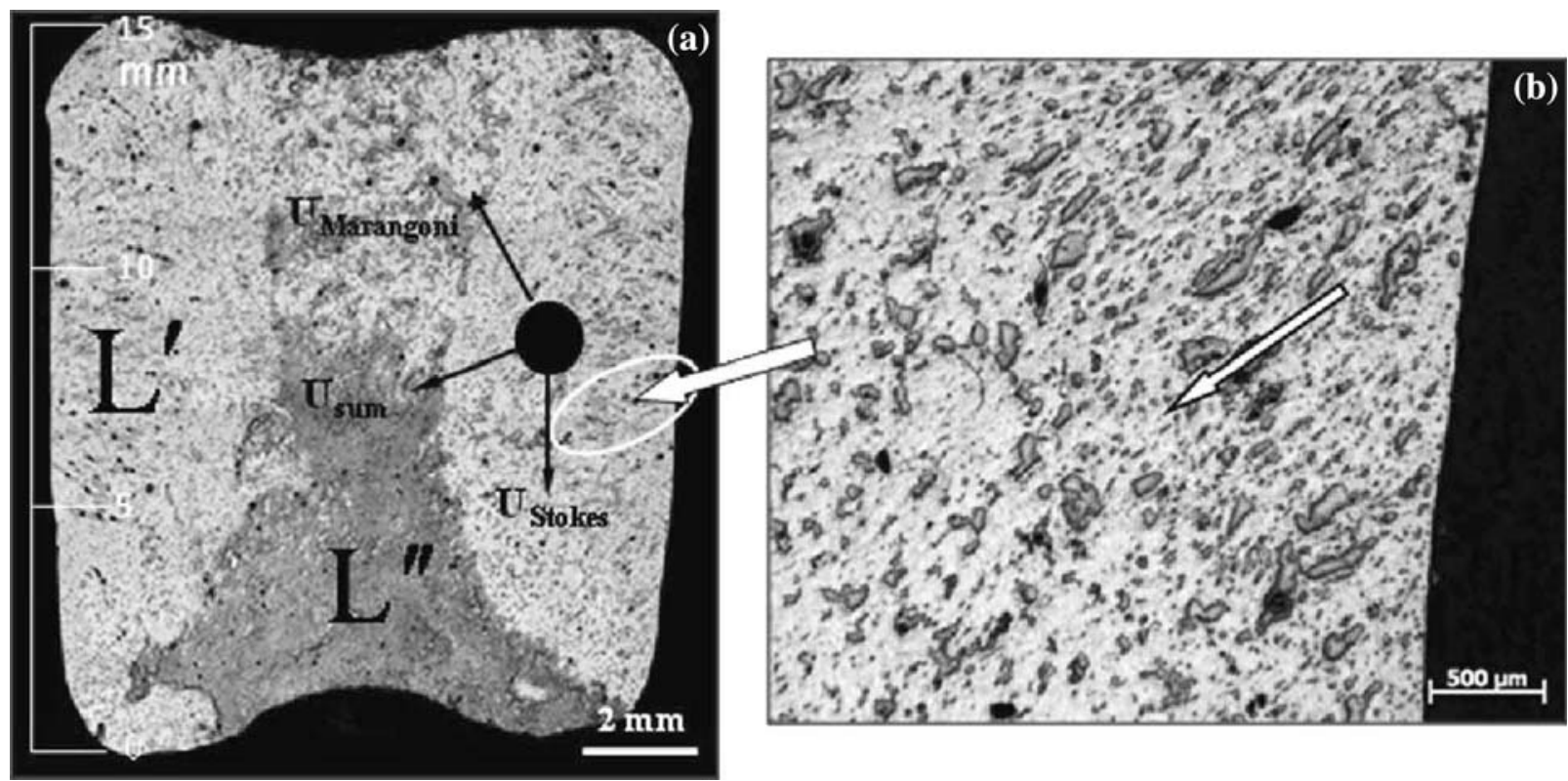

Fig. 5- (a) OM image of phase separation in the Al-45Sn-10Cu alloy of $\mathrm{L}^{\prime}$ (white in contrast) and $\mathrm{L}^{\prime \prime}$ (dark gray in contrast) liquid in the conventional solidification process (sample cast into a steel mold directly from $650^{\circ} \mathrm{C}$ ). (b) $\mathrm{OM}$ image from the mold wall indicating that the Sn droplets migrate toward the center of the mold driven by Stokes and Marangoni motions. 


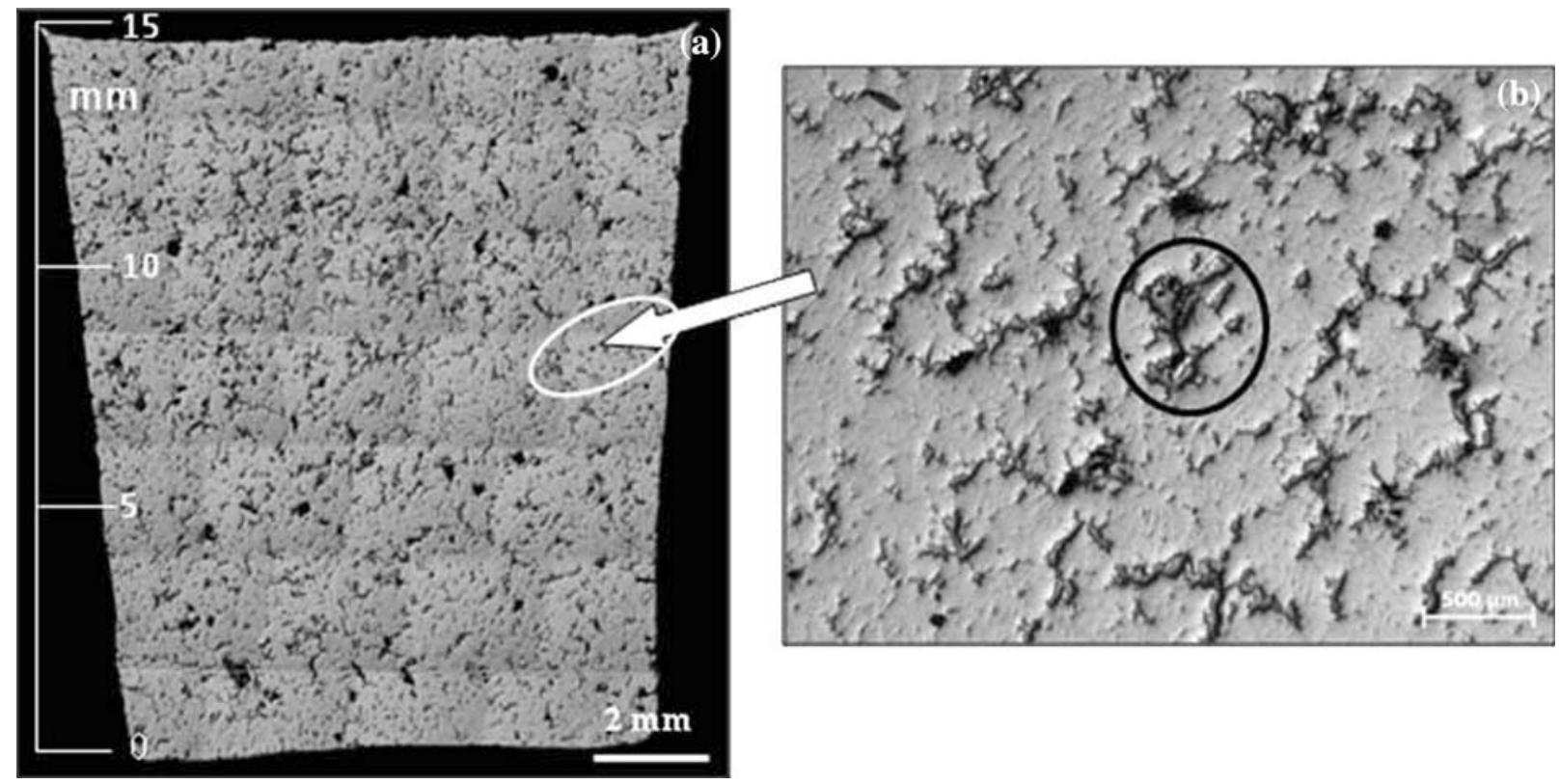

Fig. 6- (a) OM image of phase separation in the Al-20Sn-10Cu alloy of $\mathrm{L}^{\prime}$ (white in contrast) and L" (dark gray in contrast) liquid in the conventional solidification process (cast into a steel mold directly from $650^{\circ} \mathrm{C}$ ). (b) High-magnification OM micrograph showing the Sn-rich phase trapped between the primary $\mathrm{Al}$ dendrites.

the $\mathrm{L}^{\prime \prime}$ regions solidify, forming mainly pure Sn particles in the eutectic reaction at $227^{\circ} \mathrm{C}$. Both these reactions have been clearly identified on the DSC curve in Figure 4.

\section{B. Microstructure of HPDC and MC-HPDC Samples}

In order to assess the effect of intensive melt shearing on the dispersion of the soft Sn-rich phase in the hard Al-rich matrix, both Al-45Sn-10Cu and Al-20Sn-10Cu alloys were processed by both HPDC and MC-HPDC processes. The obtained microstructures of the two alloys processed under different conditions are presented in Figure 7. The most significant difference between the microstructures of the HPDC and MC-HPDC samples (Figure 7) is that a very much finer microstructure is achieved with the MC-HPDC process. The distribution of the soft Sn particles (dark gray in the OM images) is also much more uniform, particularly for the Al-45Sn$10 \mathrm{Cu}$ alloy sample. This indicates that intensive shearing affects the microstructure of immiscible alloy castings through droplet interaction, including rupturing, coalescence, and suspension. ${ }^{[22]}$

The mechanism of the microstructural evolution and particle distribution for the Al-45Sn-10Cu alloy can be summarized as follows: In the MC-HPDC process, when the alloy is fed into the MCAST machine (above the $T_{c}$ ), the melt is cooled quickly to the barrel temperature set by the control system, which is usually just below the monotectic temperature $\left(T_{m}\right)$. Under the intensive shearing and powerful dispersive mixing action created by the twin screws, the liquid droplets attain a fine particle size. This is a result of the dynamic equilibrium between two opposite processes, coagulation and breakup of liquid droplets. Inside the
MCAST unit, the slurry flow direction is opposite to the direction of the screw rotation, which means that the shear rate direction is opposite to the direction of the fluid velocity, and the turbulence leads to the formation of a round shape of droplets as well as accelerating the rupturing. The stages of the process from the homogeneous liquid to fine and uniformly distributed $\mathrm{Sn}$ particles in an Al matrix are shown schematically in Figure 8.

The final size of liquid droplets will be dictated by the intensity of the shear mixing action and the thermophysical properties of the system, such as viscosity and interfacial tension. It is well known that the viscosity of the melt increases exponentially with the volume fraction of the solid phase and decreases dramatically with an increase in the shear rate and shear time. ${ }^{[29]}$ Through careful selection of the processing temperature, the viscous force was kept high enough to counterbalance the gravity force. Also, it has been experimentally confirmed that it is easier to break up liquid droplets when the viscosity ratio falls within $0.3<\lambda<1.5$ (where $\lambda$ is the viscosity ratio between two liquids). ${ }^{[30]}$ Consequently, the alloy system is stabilized before the final solidification of the remaining liquid takes place. Therefore, higher viscosity helps to inhibit agglomeration by slowing the diffusion of the Sn droplets. The effect of the viscosity of the semisolid slurry on the Stokes $\left(U_{s}\right)^{[31]}$ and Marangoni motions $\left(U_{m}\right)^{[32]}$ is given by

$$
\begin{gathered}
U_{s}=\frac{2 g \Delta \rho\left(\eta+\eta^{\prime}\right)}{3 \eta\left(2 \eta+3 \eta^{\prime}\right)} r^{2} \\
U_{m}=\frac{2\left|\frac{d T}{d x}\right|\left|\frac{d \sigma}{d T}\right| \kappa}{\left(2 \eta+3 \eta^{\prime}\right)\left(2 \kappa+\kappa^{\prime}\right)} r
\end{gathered}
$$



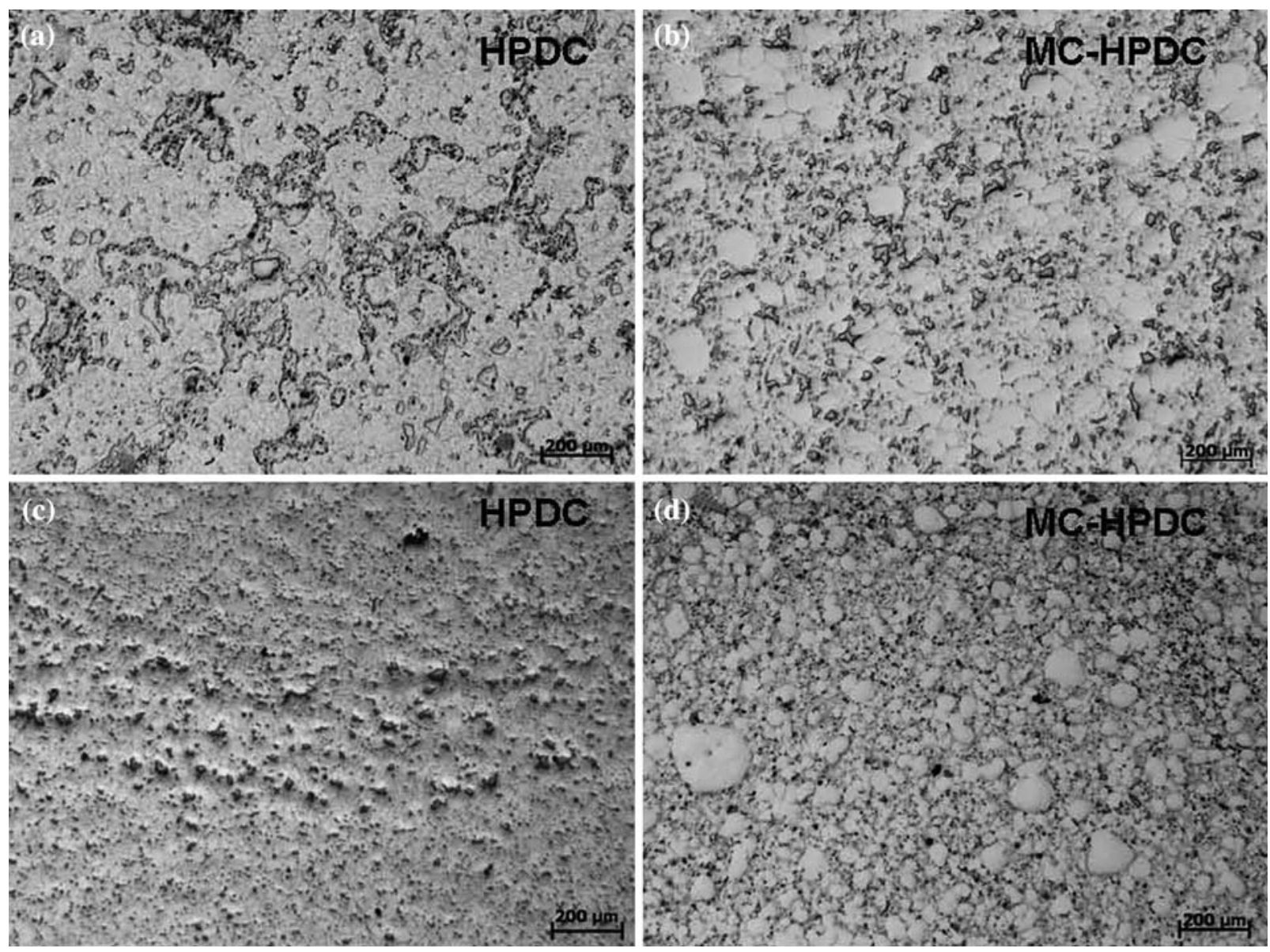

Fig. 7-Typical OM images of HPDC and MC-HPDC samples: (a) and (b) Al-45Sn-10Cu alloy and (c) and (d) Al-20Sn-10Cu alloy.

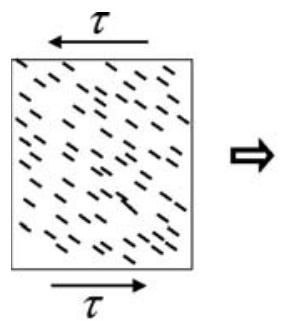

(a)

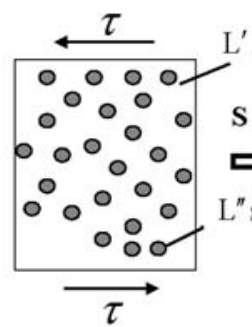

(b)

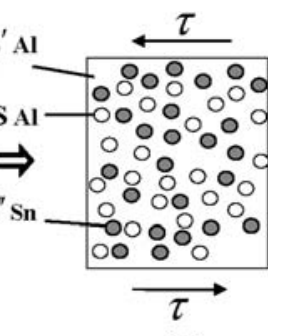

(c)

Cooling

Fig. 8 - Schematic illustration of the rheomixing process to achieve a uniform distribution of the soft phase in an Al alloy matrix: (a) homogeneous liquid (above the $T_{c}$ ), (b) creation of the L" droplets in the $\mathrm{L}^{\prime}$ matrix, and $(c)$ rheomixing: formation of a primary $\mathrm{Al}$ solid phase $(\mathrm{S})$ in the $\mathrm{L}^{\prime}$ matrix through a monotectic reaction.

where $\Delta \rho$ is the density difference between the two liquids; $g$ is the acceleration due to gravity; $r$ is the radius of the liquid droplet; $\kappa$ and $\kappa /$ are the thermal conductivities of the liquid matrix and droplets, respectively; $\eta$ and $\eta \prime$ are the viscosities of the liquid matrix and droplets, respectively; $d T / d x$ is the temperature gradient; and $d \sigma / d T$ is the variation of the interfacial energy between the two liquid phases with a change in temperature. During intensive shearing, the melt temperature is uniform throughout the entire volume of the

liquid mixture. According to Eq. [5], $U_{m}=0$; therefore, segregation of $\mathrm{L}^{\prime \prime}$ droplets is negligible during solidification of the intensively sheared melt. The high viscosity and small size of the $\mathrm{Sn}$ droplets also slow the gravitational segregation according to Eq. [4].

The microstructures produced after shearing with a variation of time and intensity were also characterized for their respective volume fractions of Sn and primary $\mathrm{Al}$ particles.

\section{Effect of shearing time}

Experiments were carried out to investigate the effect of shearing time on the size of the Sn particles for Al-45Sn-10Cu alloy. The melt was fed into the MCAST machine at $650{ }^{\circ} \mathrm{C}\left(>T_{c}\right)$ and was sheared at $535^{\circ} \mathrm{C}$ and $800 \mathrm{rpm}$ for 60, 120, and 180 seconds. Figure 9(a) shows the average Sn particle size as a function of shearing time, where the value corresponding to 0 seconds stands for the conventional HPDC processed sample. It can be seen from Figure 9(a) that the average Sn particle size significantly decreases from $1 \mathrm{~mm}$ to $33 \mu \mathrm{m}$ by applying the intensive shearing rate for just 60 seconds. A further increase in the shear time from 60 to 180 seconds resulted in only minor further refinement of the $\mathrm{Sn}$ particle size. No significant segregation has been observed in the tensile specimen, as shown in Figure 7(b). Both Sn and primary Al particle volume 


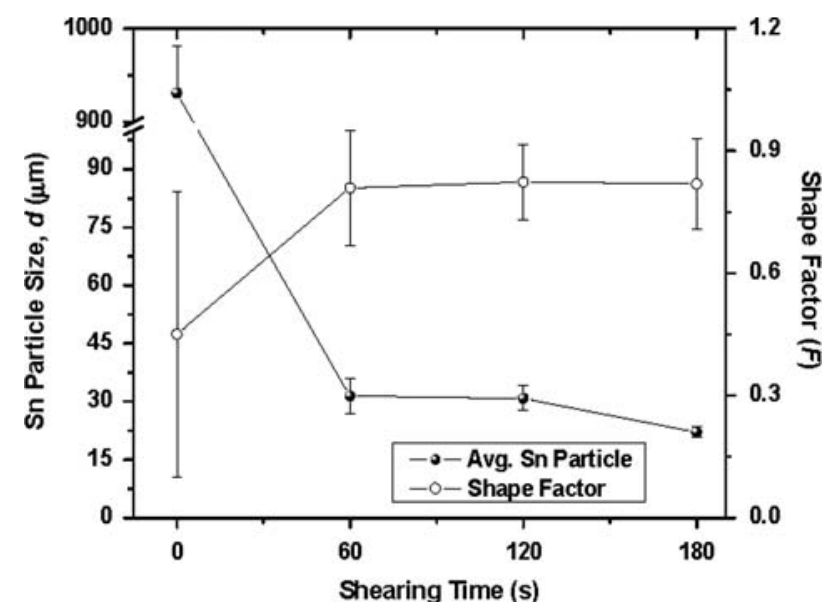

(a)

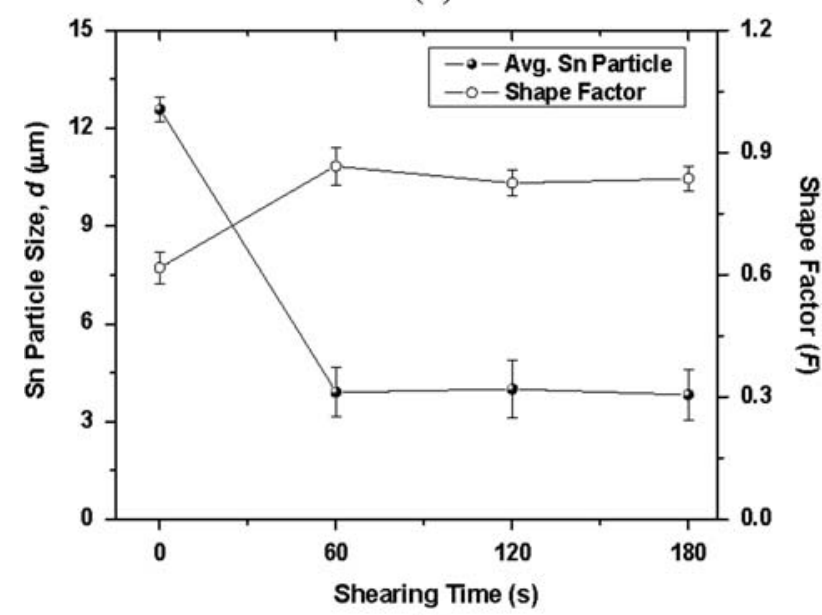

(b)

Fig. $9-$ Sn particle size and shape factor as a function of shearing time (s): (a) $\mathrm{Al}-45 \mathrm{Sn}-10 \mathrm{Cu}$ alloy- $T_{p}=535^{\circ} \mathrm{C}$ and shearing speed $=800 \mathrm{rpm}$; and $(b) \mathrm{Al}-20 \mathrm{Sn}-10 \mathrm{Cu}$ alloy- $T_{p}=580^{\circ} \mathrm{C}$ and shearing speed $=800 \mathrm{rpm}$.

fractions are observed to be fairly constant with different shearing times, and there was also no apparent variation with shearing time observed for the primary $\mathrm{Al}$ particles size and shape factor. For the Al-20Sn- $10 \mathrm{Cu}$ alloy, Figure 9(b) shows that 60 seconds is the optimized shearing time, when processing at $585^{\circ} \mathrm{C}$ and $800 \mathrm{rpm}$.

\section{Effect of shearing speed}

The intensity of shearing measured by the screw rotation speed (Eq. [1]) had a strong effect on the formation of Sn particles. It is observed that solidification under a high shearing speed and a high intensity of turbulence produces fine and spherical Sn particles with a uniform distribution in the entire volume of the sample, as shown in Figures 7(b) and (d). In the present investigation, the range of shearing speeds selected for both alloys varied from 200 to $800 \mathrm{rpm}$, and the value corresponding to $0 \mathrm{rpm}$ in Figure 10 represents the conventional HPDC process. The shearing temperatures of $535{ }^{\circ} \mathrm{C}$ and $580{ }^{\circ} \mathrm{C}$ and shearing times of 180 and 60 seconds were selected for the

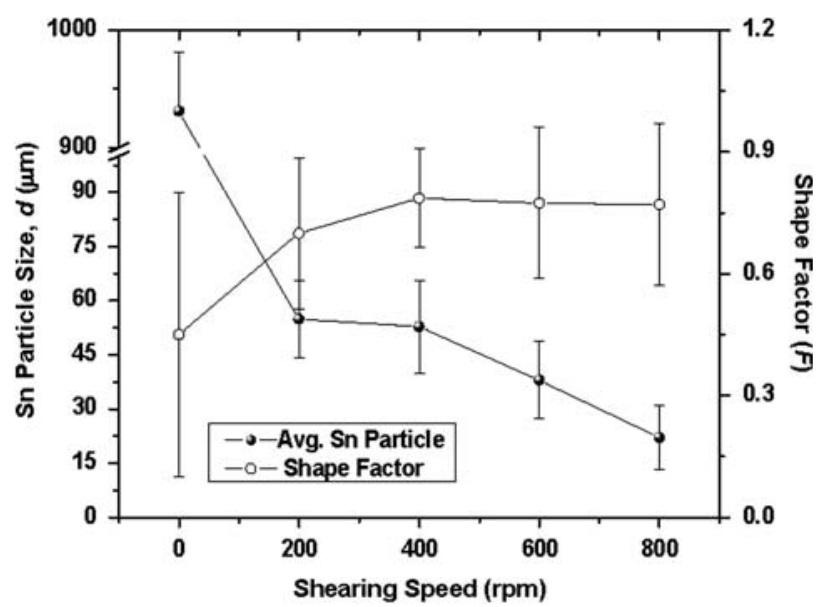

(a)

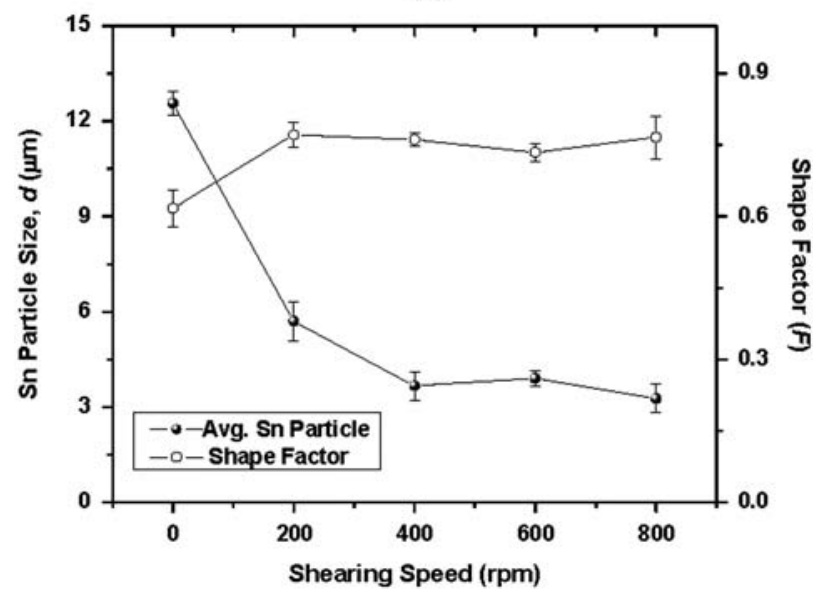

(b)

Fig. 10 - Sn particle size and shape factor as a function of shearing speed (rpm): (a) Al-45Sn-10Cu alloy- $T_{p}=535{ }^{\circ} \mathrm{C}$ for $180 \mathrm{~s}$; and (b) Al-20Sn-10Cu alloy- $T_{p}=580{ }^{\circ} \mathrm{C}$ for $60 \mathrm{~s}$.

Al-45Sn-10Cu and $\mathrm{Al}-20 \mathrm{Sn}-10 \mathrm{Cu}$ alloys, respectively. Under such experimental conditions, the average Sn particle size and shape factor for both alloys are presented in Figure 10.

In the $\mathrm{Al}-45 \mathrm{Sn}-10 \mathrm{Cu}$ alloy, the $\mathrm{Sn}$ particle size has significantly decreased from $1 \mathrm{~mm}$ to $55 \mu \mathrm{m}$ by shearing at $200 \mathrm{rpm}$. This is a significant reduction in Sn particle size, compared with the conventional HPDC process. By further increasing the shear speed from 200 to $800 \mathrm{rpm}$, the Sn particle size has been reduced from 55 to $22 \mu \mathrm{m}$, as shown in Figure 10(a). For the Al-20Sn-10Cu alloy sample, the Sn particle size was measured to be $13 \mu \mathrm{m}$ (Figure 10(b)), as produced by the conventional HPDC process. This Sn particle size is very small compared to the conventional HPDC Al-45Sn-10Cu alloy samples. The reason for this is that primary Al particle precipitation occurs first before demixing of the liquid, as mentioned previously, and also the Sn concentration is lower compared to the Al-45Sn-10Cu alloy. However, by applying shearing to the $\mathrm{Al}-20 \mathrm{Sn}-10 \mathrm{Cu}$ alloy, the Sn particle size was reduced from 13 to $3 \mu \mathrm{m}$ at $800 \mathrm{rpm}$ for 60 seconds. Both the Sn and primary Al particle morphology are quite close to the spherical. 
Figures 10(a) and (b) clearly show that the size of the Sn particles was significantly decreased and the shape factor increased with increasing shearing speed.

Figures 7(a) and (c) illustrate that Sn particles are severely segregated in the conventional HPDC process for both alloys. In contrast, Figures 7(b) and (d) show that homogeneous microstructures of the soft phase in the $\mathrm{Al}$ matrix were achieved after intensive shearing in the semisolid region. It is also observed that intensive shearing helps to increase the number of Sn particles as a result of the reduced particle size shown in Figure 7. It was observed that a decrease in Sn particle size with shearing is not only related to the breakup process but also due to the shear-induced coalescence. The coalescence can be accelerated by the same factors that favor the drop breakup, i.e., high shear rate and reduced viscosity ratio. Therefore, the minimum droplet size under given shear mixing conditions is a dynamic balance between two opposite processes, droplet breakup and coalescence.

Quantitative analyses of the distribution were done by the Quadrat method. ${ }^{[25]}$ Figures 11(a) and (b) show the frequency of scatter according to the number of particulates per Quadrat, $N q$, together with the theoreti$\mathrm{cal}^{[25,33]}$ statistical distribution curves (solid line). Figures 11(a) and (b) reveal that the soft phase distribution in the Al matrix is close to the Poisson and the Binomial distributions from the MC-HPDC process, while the HPDC process results in a segregated distribution expressed by a negative Binomial curve. It can be seen from these quantitative results and microstructures that the intensive shearing process offers a better distribution of the soft phase throughout the entire volume of the sample compared to conventional methods. ${ }^{[25,33]}$

\section{CONCLUDING REMARKS}

Using advanced computational thermodynamic techniques, two model immiscible alloys, $\mathrm{Al}-45 \mathrm{Sn}-10 \mathrm{Cu}$ and Al-20Sn- $10 \mathrm{Cu}$, were selected to investigate the feasibilities of producing fine and uniformly distributed soft $\mathrm{Sn}$ particles in a relatively hard Al-Cu alloy matrix by way of a novel MCAST process. First, our experimental results on HPDC of the immiscible alloys with and without melt shearing have confirmed that intensive melt shearing can greatly assist the dispersion of the soft Sn phase without the occurrence of macro-demixing. Second, the effect of solidification path on the dispersion of the soft Sn particles was investigated by gravity die casting. It is found that the immiscible alloys with the precipitation of the primary $\mathrm{Al}$ particles prior to the demixing reaction (such as $\mathrm{Al}-20 \mathrm{Sn}-10 \mathrm{Cu}$ ) more easily obtain a fine and uniform dispersion compared with those alloys with a demixing reaction before the precipitation of the primary $\mathrm{Al}$ particles (such as Al-45Sn-10Cu). Finally, the effect of shearing time and shearing speed of the MCAST process on the size and uniformity of the dispersed Sn phase was investigated. It was found that melt shearing at $200 \mathrm{rpm}$ and 60 seconds is adequate to produce fine and uniform dispersion of

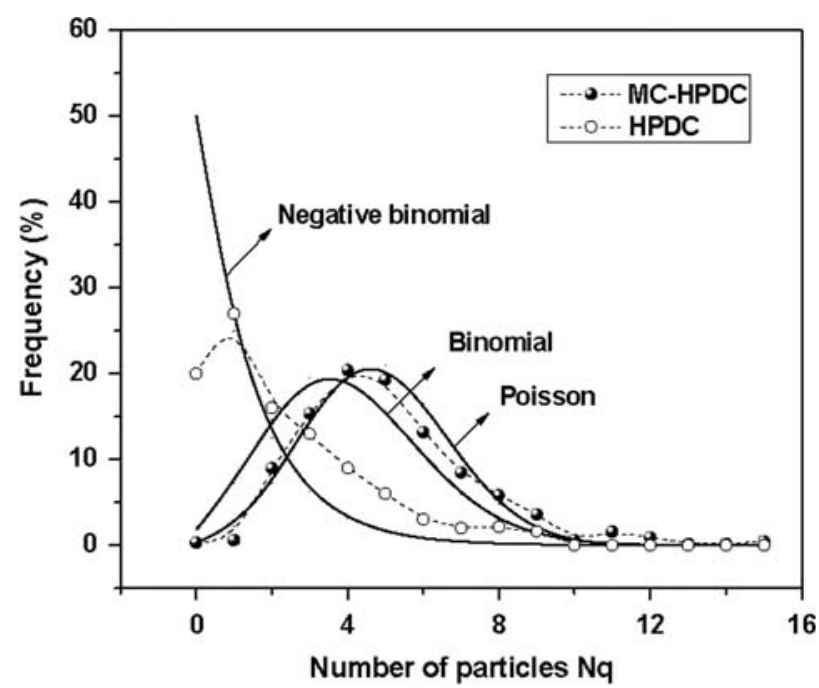

(a)

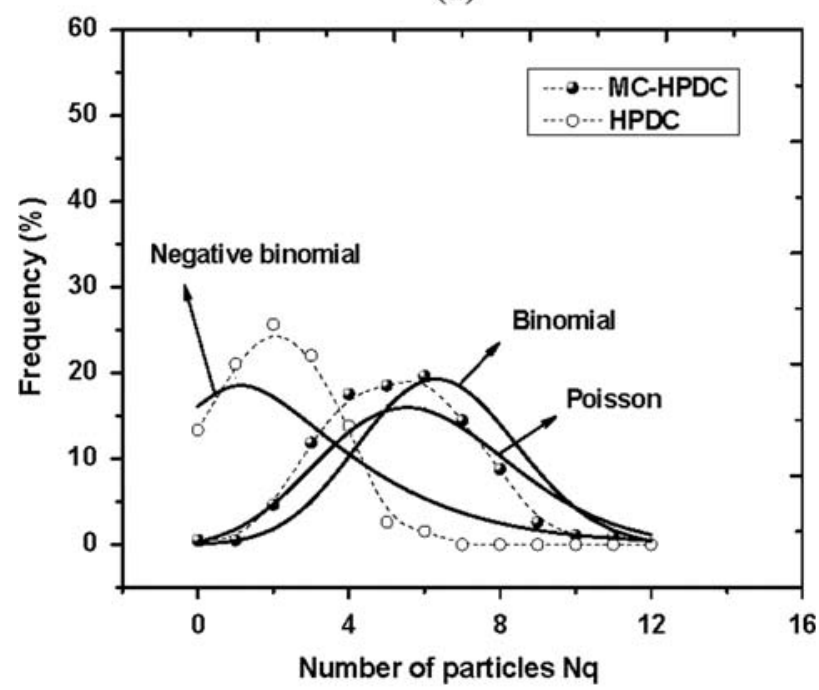

(b)

Fig. 11-Sn particle size distribution for HPDC and MC-HPDC samples in comparison with other theoretical distribution curves for (a) $\mathrm{Al}-45 \mathrm{Sn}-10 \mathrm{Cu}$ alloy and (b) $\mathrm{Al}-20 \mathrm{Sn}-10 \mathrm{Cu}$ alloy.

the Sn phase, and that higher shearing speed and prolonged shearing time can only achieve minor further refinement.

\section{ACKNOWLEDGMENTS}

This study has been funded by the EPSRC and DTI. The authors thank Dr. N. Hari Babu for useful discussions and also Dr. H. Men for help conducting DSC experiments.

\section{REFERENCES}

1. L. Ratke and S. Diefenbach: Mater. Sci. Eng. R, 1995, vol. 15R, pp. 263-347.

2. Immiscible Liquid Metals and Organic (Proc. Immiscible Alloys, Physikzentrum, Bad Honnef, 1992), L. Ratke, ed., DGM Informationsgesellschaft mbH, Oberursel, Germany, 1993, pp. 199-258 and $261-310$. 
3. Aluminum and Aluminum Alloys, J.R. Davish, ed., ASM INTERNATIONAL, Materials Park, OH, 1993, 93 pp.

4. C.J. Kong, P.D. Brown, S.J. Harris, and D.G. McCartney: Mater. Sci. Eng. A, 2005, vol. 403A, pp. 205-14.

5. L. Ratke, G. Korekt, and S. Drees: ESA Symposium Processing on 'Space Station Utilisation,' ESOC, Darmstadt, Germany, Sept. 30 Oct. 2, 1996, pp. 247-51.

6. X. Fang and Z. Fan: Scripta Mater., 2006, vol. 54, pp. 789-93.

7. H.R. Kotadia, J.B. Patel, Z. Fan, E. Doernberg, and R. SchmidFetzer: Solid State Phenomena, 2008, vols. 141-143, pp. 529-34.

8. H.R. Kotadia, J.B. Patel, Z. Fan, E. Doernberg, and R. SchmidFetzer: Aluminium Alloys: Fabrication, Characterization and Applications II 2009, San Francisco, CA, 2009, W. Yin, S.K. Das, and Z. Long, eds., TMS, Warrendale, PA, 2009, pp. 81-86.

9. L. Yuan, L. Yan-Xiang, G. Jing-Jie, J. Jun, S. Yan-Qing, and D. Hong-Sheng: Trans. Nonferrous Met. Soc. China, 2002, vol. 12, pp. $357-65$.

10. J. Shima, H. Leeb, H.P. Haa, Y.W. Choa, and E. Yoonc: J. Alloys Compd., 2001, vol. 327, pp. 270-74.

11. J.Z. Zhao and L. Ratke: Scripta Mater., 2004, vol. 50, pp. 543-46.

12. N. Wang and B. Wei: Mater. Sci. Eng. A, 2003, vol. 345A, pp. $145-54$.

13. H.X. Peng and Z. Fan: J. Mater. Sci. Lett., 2001, vol. 20, pp. 1769-71.

14. Z. Fan, M.J. Bevis, and S. Ji: PCT Patent WO 01/21343 A1, 1999.

15. D. Mirkovic, J. Groebner, and R. Schmid-Fetzer: Mater. Sci. Eng. A, 2008, vol. 487A, pp. 456-67.

16. D. Mirkovic, J. Groebner, and R. Schmid-Fetzer: Acta Mater., 2008, vol. 56, pp. 5214-22.

17. H.L. Lukas, S.G. Freis, and B. Sundman: Computational Thermodynamics - The Calphad Method, Cambridge University Press, Cambridge, United Kingdom, 2007.
18. PANDAT TM Software for Multiplecomponent Phase Diagram Calculation, Computherm LLC, Madison, WI.

19. H. Tang, L.C. Wrobel, and Z. Fan: Comp. Mater. Sci., 2004, vol. 29 , pp. $103-18$.

20. H. Tang, L.C. Wrobel, and Z. Fan: Mater. Design, 2006, vol. 27, pp. 1065-75.

21. H. Tang and L.C. Wrobel: Int. J. Eng. Sci., 2005, vol. 43, pp. $1234-56$

22. H. Tang, L.C. Wrobel, and Z. Fan: Appl. Phys. A, 2005, vol. 81A, pp. 549-59.

23. Z. Fan and G. Liu: Acta Mater., 2005, vol. 53, pp. 4345-57.

24. Z. Fan: Mater. Sci. Eng. A, 2005, vols. $413 \mathrm{~A}-414 \mathrm{~A}$, pp. $72-78$.

25. P.A. Karnezis, G. Durrant, and B. Cantor: Mater. Characterization, 1998, vol. 40, pp. 97-109.

26. A. Munitz and R. Abbaschian: Mater. Trans. A, 1996, vol. 27A, pp. 4049-59.

27. M.B. Robinson, D. Li, T.J. Rathz, and G. Williams: J. Mater. Sci., 1999, vol. 34, pp. 3747-53.

28. S. Curiotto, N.H. Pryds, E. Johnson, and L. Battezzati: Mater. Trans. A, 2006, vol. 37A, pp. 2361-68.

29. Z. Fan: Int. Mater. Rev., 2002, vol. 47, pp. 49-85.

30. Z. Fan, S. Ji, and J. Zhang: Mater. Sci. Technol., 2001, vol. 17, pp. $837-42$.

31. V.G. Levich: Physicochemical Hydrodynamics, Prentice-Hall, Englewood Cliffs, NJ, 1962.

32. N.O. Young, J.S. Goldstein, and M.J. Block: J. Fluid Mech., 1959, vol. 6 , pp. $350-56$.

33. A. Rogers: Statistical Analysis of Spatial Distribution-The Quadrant Method, 3rd ed., Pion, London, 1974. 